\title{
A Dynamic Assessment of the François-Mitterrand Library
}

\author{
Valerie Vesque-Jeancard \\ Deputy CEO of Bibliothèque nationale de France, Site François-Mitterrand, \\ Quai François-Mauriac, 75706 Paris Cedex 13, France, \\ valerie.vesque-jeancard@bnf.fr
}

\begin{abstract}
A powerpoint presentation containing photographs of the library is available from http://www.zhbluzern.ch/liber-lag/PP LAG 08/Tuesday/Vesque Jeancard-LIBER presentation BnF def.pdf; a virtual tour of the library is available at http://www.bnf.fr/visitefmitterrand/promenade/rec pp.htm.
\end{abstract}

\begin{abstract}
The François-Mitterrand Library, main site of the Bibliothèque nationale de France (BnF), was built in 1993 by architect Dominique Perrault. The library, which hosts 13 million documents, welcomes 3,500 visitors per day, either for consultation of documents in its majestic reading rooms or for conferences and exhibitions. The evolution of services provided to the library's visitors (increase in electronic resources for instance), the broadening of the BnF's users (from researchers to a broader public, including professionals and young people), the change in the building's environment (public transportation, urban extension, etc.) along with the evolution of regulations (facilities for the disabled, etc.) or, more recently, increased consideration for sustainable development, led to a continuous adaptation of the building throughout the last 15 years. This dynamic assessment will continue to be a key factor for the library to successfully face future challenges.
\end{abstract}

Key Words: Academic libraries; France; carbon footprint; energy audit; accessibility 
The François-Mitterrand Library is the main site of the National Library of France (BnF), an institution located at seven different sites, five of which are open to the public and offer reading rooms, exhibitions and conferences, and two of which are technical centres where books are being stored, digitised and cared for.

\section{The François-Mitterrand Library's Origin and Main Features}

The François-Mitterrand Library was designed by French Architect Dominique Perrault, chosen in 1989 after an international architecture contest with architect Pei as president of the jury. Construction began in 1991 and the building was inaugurated in 1995.

\section{A Home for the Printed Books and Audiovisual Collections of the Bibliothèque nationale de France}

The library was designed to be the home of all the printed books of the $\mathrm{BnF}$, as well as audiovisual documents, whereas other types of documents ('specialized' documents such as manuscripts, photographs and engravings, maps and globes, coins, medals and antiques, music scores, costumes, theatre setting models, etc.) remained in the historic building of Richelieu located in the very centre of Paris.

The François-Mitterrand Library was intended to be open to a very large public, which led to the creation of two different libraries inside. The 'Hautde-jardin' library, open to everyone over 16 years old, resembles a public library, with open access to a number of books but no access to patrimonial collections, whereas the 'Rez-de-Jardin' library is a research library, open to those who can prove they need access to the library's patrimonial collections for research purposes. The 'Haut-de-jardin' library opened on December 2, 1996. The 'Rez-de-jardin' library welcomed its first researchers on October 8, 1998.

The comfortable and beautiful reading rooms offer 3,314 seats: 1,642 seats in Haut-de-jardin and 1,672 seats in Rez-de-jardin. They are organised for a 
maximum interaction between books and readers, with 600,000 documents in open access (out of the 13 million printed books that are kept in the library). One million seventy thousand documents are being handled every year in the Rez-de-Jardin research library.

\section{A Gigantic Building}

Symmetry is one of the main features of the building, which is laid out as a rectangle (approximately 400 metres long and 200 metres wide), with four glass towers at each corner (looking like open books). The towers are named either with numbers (from 1 to 4 ) or with names, referring to the thematic departments they shelter (Time, Law, Letters and Numbers).

Levels 1 and 2 of the towers are almost empty (with just a welcome space for people who come to visit the BnF staff), thus acting like a light well for the reading room accesses underneath. Levels 3 to 9 are office space, while levels 10 to 20 shelter stacks (except for two of the towers, in which level 20 is dedicated either to computer fittings or to conference rooms). Levels 21 and 22 , just under the flat roof, are used for various technical fittings. The towers' height totals 79 metres from the esplanade to the top.

An important part of the building is located under the esplanade level. Here we find the public halls and reading rooms, which are organised in a rectangle shape, on two levels, around a central secluded garden (190 metres long, 58 meters wide), like a cloister. More stacks can also be found in the basement, arranged like a belt around the reading rooms. The esplanade and the garden level are 23 metres apart, which gives an idea of the majestic dimensions of the reading rooms. An automated transfer system allows documents stored in the upper levels of the four towers to be brought to the reading rooms.

There are two entrances for the public, east and west, on each small side of the garden rectangle. Visitors descend into the library from the esplanade level. The very first project of the architect included a unique and monumental entrance on the bank of the river Seine, leading to a commercial gallery. As 
Table 1: François Mitterrand Library in facts and figures.

\begin{tabular}{|c|c|}
\hline Total floor surface area (inc. esplanade) $: 365,000 \mathrm{~m}^{2}$ & Inner garden surface area : $11,000 \mathrm{~m}^{2}$ \\
\hline $\begin{array}{l}\text { Net surface area : } \mathbf{1 6 0} 000 \mathrm{~m}^{2} \text {, including: } \\
-58000 \mathrm{~m}^{2} \text { of stacks, } \\
-55000 \mathrm{~m}^{2} \text { of public space, } \\
-17000 \mathrm{~m}^{2} \text { of office space. }\end{array}$ & $\begin{array}{l}\text { Reading rooms : } 40000 \text { m² }^{2} \\
\text { - } 9 \text { Haut-de-jardin rooms, } \\
\text { - } 14 \text { Rez-de-jardin rooms. }\end{array}$ \\
\hline
\end{tabular}

library services finally prevailed, this scheme was abandoned, leading to the current lay-out.

Finally, the esplanade can be reached by stairs when coming from the north from the river Seine or the east/west sides, while it is at the same level as the road running parallel to the south side of the Library.

\section{A Continuous Evolution, Still in Progress}

The building underwent continuous adaptations throughout the last 15 years, for several reasons. For instance, the library had to adapt to changes in its urban environment; when it was built, there was almost nothing around, a situation which has dramatically changed in the recent years. Also, the operation of the library had to be optimised from the budgetary point of view, leading to choices in the manner services are provided. Improvement of services to the public, better accessibility for disabled people to access site and services, along with the improvement of working conditions for the staff, were also key factors for change. Last but not least, more pressing environmental concerns also pleaded for a change.

\section{Beneficial Changes, Outside as well as Inside the Library}

\section{Adaptation to a Mutating Urban Environment}

The remote and empty space in which the library was built underwent several changes after the opening. In 2001, a broad street, called avenue de France, was created along the south side of the library, allowing for easier access; the same year, a new subway line 'Meteor' opened, with one of its 
stations close to the east entrance of the library. Linking the area with the very centre of Paris, the Meteor subway line is entirely automated (which means that strikes do not prevent it from working) and very fast. It dramatically changed the way visitors access the library, with the east entrance taking the lead: in $2007,75 \%$ of all visitors entered the library from that side.

Afterwards, in 2006, a temporary pedestrian bridge was opened over the south railway, allowing easier connection with the southern areas of the library from the Avenue de France. Also a very nice wooden pedestrian bridge named after French writer Simone de Beauvoir was built over the river Seine, enabling a direct connection between the esplanade and the other bank of the river with its Bercy gardens, the Ministry of Economy and Finances, restaurants, a commercial centre, etc. In the summer of 2006, a floating swimming pool was created on the river, at the very foot of the library. Several restaurants and shops also opened in the area, making the urban environment more and more friendly and giving the library a central role.

In this connection, something had to be done to signal the way into the library more efficiently, enable the visitors to follow a safe route to the entrance and enhance the integration of the building in its urban environment. Indeed, visitors had a hard time finding their bearings in the metal and wooden universe prevailing on the esplanade, with escalators barely visible. Also, the ipé wood of the esplanade proved to be very slippery with rain or frost. Finally, the introverted nature of the building (one has to climb the stairs to descend into the building) had to be compensated for.

An architecture contest was launched in 2006 to modify the access and public areas of the library (outside and inside); three architects were requested to submit a study. Unfortunately, the BnF could not get the budget to carry out any of the three projects. We nevertheless decided to launch an outside project a minima, the studies for which have just been finished and the realisation of which will begin in October 2008. The project comprises a secured path on the esplanade: non-slippery, lit at night, with guiding lines and sound markers for the visually impaired. It includes gigantic totems to signal the entrance, as well as urban furniture, such as benches, for people to stop and rest, or relax while enjoying the garden view. Existing architectural elements will also be coloured to act as markers along the path. 
Thanks to this project, the esplanade shall become a more welcoming place for visitors. It is already more lively, thanks to various cultural events: a.o., concerts organized for the Fête de la Musique, the annual exhibition of contemporary installations by the students of École Nationale Supérieure des Arts Décoratifs, performances for the annual Nuit Blanche event. Also, since the Spring of 2008, a big tent called Le Dansoir is allowed to settle on the esplanade for six months each year, offering dance and theatre shows. Finally, since 2007 , the library opens its garden to visitors once a year, during the national Rendez-vous aux jardins event.

\section{Improvement of Inside Organisation and Enhancing the Library's Cultural Offer}

When the library was built, the Rez-de-Jardin reading rooms, at the lower level, could be accessed by four gigantic escalators coming from the Hautde-Jardin level, at each corner of the rectangle. This system proved to be far too demanding in terms of staff needed for security and orientation, as well as in terms of operating costs. And it rapidly turned out that two points of access were enough to cope with the number of visitors to the library.

The reduction of the Rez-de-Jardin accesses from four to two created room at the Haut-de-jardin level for other purposes. It enabled the library to create two permanent exhibition rooms at this level, very near to the entrance of the halls, in addition to the two existing galleries for temporary exhibitions.

In 2005, L'espace découverte was opened to the public in the east entrance hall. It comprises a small exhibition about the BnF's history, as well as audiovisual presentations with interviews of readers and BnF staff. But the most frequented part of L'espace découverte is the place where various items from the $\mathrm{BnF}^{\prime}$ s collections are displayed, showing their variety and uniqueness. The display is changed every three months and each month, one particular item receives special attention: either a recent acquisition or donation, or a collection item linked to current events (such as anniversaries). For most visitors, this place is their first contact with the library.

In October 2006, the Coronelli globes joined a permanent presentation corner in the west entrance hall of the library. Those two globes, which date back to 1683 and were designed by the Venetian monk Vincenzo Coronelli for king 
Louis $\mathrm{XIV}$, represent the world as it was known at the time as well as the sky the very night of the birth of the king. They are the biggest objects kept in the library and they refer to the historic site of Richelieu, where the rest of maps and globes of the Bibliothèque nationale de France are conserved. The exhibition area also comprises a presentation about cartography, ancient and contemporary.

Step by step, the initial symmetry between the east and the west halls is disappearing. The eastern hall is the way in for more than three fourths of the library's visitors: it is the main entrance now, with a welcome desk, cloakroom, reader orientation services, exhibition tickets sale booths, L'espace-découverte, a bookstore and café and the 'Friends of the $\mathrm{BnF}^{\prime}$ association desk. The west entrance hall is gradually becoming a hall for special events, with 'Les globes de Coronelli' and reproduction services, activities for young visitors as of September 2008 and a small exhibition gallery (for donations for instance) as of the end of 2009. Also, the western hall is used for private receptions. The west cloakroom, reader orientation services and welcome desks are gradually being closed.

\section{Constant Improvement in Several Fields}

\section{Facilities for the Public}

When the library was opened, welcome desks were not so welcoming, as the staff seemed to hide behind the wooden panels, which gave a dull and uncommunicative impression. After a few years, those panels were removed and the welcome desk is now a friendly place, immediately visible for the visitors upon entry.

Another example is the 'Club chercheurs' in the Rez-de-jardin library: comfortable and bright places where readers can drink, eat, relax and talk in a loud voice, enabling a pause in their work. The library scheme initially did not include such places.

A lot was also done to help disabled people access the premises as well as the collections. Relief mock-ups of the Coronelli globes have, for instance, been 
installed thanks to private sponsorship, as well as audio devices for visually impaired people. L'espace-découverte will be equipped in the same way at the end of 2008. Electromagnetic devices help the hearing impaired to communicate with BnF staff whenever they want to get information or to buy tickets, or to listen to audiovisual presentations more easily. Special booths were equipped in the reading rooms for the visually impaired to access collections.

The site itself is still not very friendly, with heavy doors to push everywhere for instance, and there is more to be done in the years to come. The BnF has just launched a thorough audit of the situation, thus anticipating the regulatory deadline of 2010 for this diagnosis.

\section{Care of the Collections}

The building also had to evolve with regard to this core mission of the Bibliothèque nationale de France.

As far as security is concerned, the controlled access system to stacks and other sensitive parts of the library was entirely renewed in 2005 (in association with stricter authorisation rules) and volumetric alarms were implemented. Also, entrances and exits of the Haut-de-jardin reading rooms were secured to control user behaviour and loss of books.

With regard to protection against water, the library has been sheltered by a diaphragm wall since construction, as it is situated just along the Seine river. Anti-flood devices were added in 2006/2008 to prevent water from flowing back when it is evacuated. Also, since 2006 the library has been carrying out a systematic risk analysis of floods that can be caused by the building itself, as many fluids circulate everywhere; though they are not transiting the stacks, they can nevertheless have an impact on those areas. Finally, in 2007/2008, an argonite-based extinction system was implemented in the reserve for precious and rare books instead of water sprinklers.

Digital collections are also being carefully cared for. Corresponding servers are kept in a special computer room, with a mirror site $30 \mathrm{~km}$ away from Paris, linked by optical fiber cables. 


\section{Working Conditions for the Staff}

Several projects have been carried out since the library's opening to improve working conditions for the staff. Resting areas were created in the basement for people working in the stacks; reception areas in the towers were improved as far as lighting, air conditioning and space are concerned; lighting and air conditioning in the staff training rooms can now be modulated so as to adapt to occupation and activity.

\section{Environmental Concerns}

The adoption by France of the so-called Charte de l'environnement in 2005 gave sustainable development a constitutional value. It is an imperative for all, and the public sector should lead the way in this field.

Environmental concerns began to be taken into account in the way the Bibliothèque nationale de France manages its François-Mitterrand library since 2003: the BnF reduced its energy consumption (replacement of light sources, choice of low-energy office facilities), began to recycle paper, printer and photocopier toners or chemical waste, decided to maintain gardens with organic products and to purchase less polluting vehicles.

Since the summer of 2007, the BnF has structured its strategy and increased its scale. Sustainable development applied to buildings gives rise to an important number of actions to be undertaken, which must be balanced against the constraints imposed by the preservation of books and the quality of services offered to visitors, readers and researchers. Three main directions can be identified.

\section{Contribution to the Reduction of Greenhouse Gas Emissions}

The BnF's carbon footprint of activities on its seven sites was completed in March 2008, with financial and methodological help from ADEME (the French Environment and Energy Management Agency).

The carbon footprint expresses in equivalent tons of carbon the ecological impact of all the BnF's activities (functioning of buildings, storage of books, movements of staff and readers, organisation of exhibitions, etc.) in terms of greenhouse gas emissions. It leads to a ranking of the various emission 
sources so as to bring to light the critical domains and to suggest ways of progress and corrective actions.

Buildings represent an important emission source, both from the point of view of energy consumption and construction amortisation. More specifically, amortisation of the François-Mitterrand library construction accounts for $21 \%$ of the footprint, whereas energy consumption on all sites of the $\mathrm{BnF}$ accounts for $31 \%$ of the footprint. Energy saving is an important aim of BnF for the years to come.

In order to approach the problem systematically, the library decided to launch an energy audit of the François-Mitterrand library and a call for competition was published on March 3, 2008. This audit aims at analysing the energy consumption of the building and its equipment (air-conditioning, heating, warm water, elevators, staircases and escalators, lighting, telephony, access control and video surveillance, staff restaurant, motorised shelving and automatic transportation of documents).

First of all, the provider will assess the existing situation, according to the seasons and the way the various equipment and facilities are managed, in order to suggest possible ways of improvement. Once validated, these propositions will be studied in a more detailed way in order to examine the technical feasibility, to calculate the cost of the proposed works, and the impact on the energy consumption and thus the savings which can result from it. The audit should be completed at the very beginning of 2009 .

Improvements might be found both in operational adaptations and in structural modifications. First of all, changes in the modalities of exploitation can have a strong impact on energy consumption. Two examples can be given in this respect. The escalators leading from Haut-de-Jardin to Rez-de-Jardin are set in large spaces that certainly don't need to be air-conditioned thoroughly and the adjacent reading rooms have very high ceilings - why not try to limit the regulated volume to the two metres situated above ground level? Another example concerns the temperature and hygrometric conditions prevailing in the stacks $\left(18^{\circ} \mathrm{C}, 60 \%\right)$ : perhaps the stability required by preservation standards can be reached in a more flexible way which saves energy.

Structural modifications can be a second way to save energy. Several questions shall be addressed in this respect: can glass panels be changed or other 
devices be found to filter sunlight in a more efficient manner? Is there a way to recover the substantial amount of heat observed between the glass panels and the wooden shutters, especially in the higher half of the towers? Could photovoltaic energy be produced by solar panels located either on the roofs or on the façades?

Without waiting for the energy audit results, and even before it was launched, the $\mathrm{BnF}$ embarked upon a course of energy saving, and it will continue to do so:

- Light - improvement of motor control and installation of automatic extinction devices in some places, earlier extinction of the lighting in reading rooms, giving up of the night lights in stores (initially planned to prevent animals and pests from developing but which have not proved efficient; on the contrary, they enhanced the exposure of documents to light), gradual replacement of halogen light sources by metal iodide ones (energy consumption divided by three, life cycle doubled) since 2007, etc.

- Air-conditioning - modification of the regulation equipment of the air-conditioning system (by installing power regulation).

- Office equipment - choice of low-energy office facilities for several years, automatic extinction of the 600 workstations of the reading rooms at night since December 2007 (the same thing shall be done with the computers of BnF staff in September 2008), next renewal campaign for computers and printers to include significant scope reduction (for instance, use of shared printers for staff will be encouraged; as for readers, they tend to come more and more with their own laptops, as they are offered a growing number of wired-up study places, and electronic resources will soon be made available to them on line with a license).

\section{Contribution to Water Resources and Biodiversity Preservation}

The library aims at protecting water resources by reducing its consumption and limiting the pollution caused by its activities.

Various sanitary equipment consuming less water than the current ones will be tested in 2008. Also, some projects are underway involving rain water harvesting or greater use of recycled water in several technical installations. A promising idea involves harvesting rain water to stock it in tanks under the esplanade 
of the François-Mitterrand library so as to re-inject it into the air-conditioning system (after treatment) and the irrigation system of the BnF garden. Moreover, since 2007, studies have been undertaken on the possibility of recycling water vapour coming from the cooling towers (condensation, harvesting, treatment).

Besides the water resources preservation, the $\mathrm{BnF}$ intends to contribute to biodiversity protection. The central garden of the François-Mitterrand library has already been maintained according to a reasoned method using only organic products since 2003. The garden biodiversity is being presented to the public once a year since 2007 and will be inventoried this year, in association with the National Museum of Natural History.

The Museum intends to study the garden during different periods of the year to get a dynamic vision of the ecological situation according to the seasons. A comparison with the environmental state of the various Parisian gardens will allow the Museum to gather information about the biodiversity of public green areas in the city and gain a better idea of the botanical and animal evolutions of the parks. The work will probably result in an educational presentation to the public of the botanical and animal species which live in the BnF garden or use it as a stop-over.

\section{Waste Management}

The first concern in terms of waste consists in reducing its volume, of course, which implies responsible purchasing by the library (questioning the need for every act of purchase and choosing products or services producing a minimum of waste) as well as calling for responsible consumption by its staff.

The second concern involves paying particular attention to waste elimination or to its valuation by recycling. In this field, the purchase policy is also very important (in its calls for tenders, the library includes more and more criteria relative to the end of life of the purchased products). But building adaptation is also a key issue, as the implementation of recycling is very demanding: recycling containers and premises, collecting circuit, compactors, disposal system.

Recycling is already a substantial activity at the François-Mitterrand site of the $\mathrm{BnF}$ (e.g., paper, printer and photocopier toners, batteries, light bulbs, 
medical and chemical waste). In April 2008, readers were involved in paper recycling in their turn. Recycling will continue to expand at the end of 2008 thanks to the addition of three other materials to be recycled: aluminium, plastic and cardboard, which could be collected at the neighbourhood level.

\section{Conclusion}

The François-Mitterrand library has been transformed in several ways since it was built in 1993. Only some of the work done was alluded to in this article. There are many more projects ahead, some of which we already know about and some we don't know yet. The ability to make a dynamic assessment of the building's features and functioning will continue to be a key factor for the library to face future challenges. As for an assessment of the present situation, you should come and visit, either on site or on line.

\section{Websites Referred to in the Text}

ADEME, the French Environment and Energy Management Agency, http://www2. ademe.fr $/$ servlet $/$ getDoc?id $=38480 \& m=3 \& c i d=96$

Charte de l'Environnement, http://www.ecologie.gouv.fr/La-Charte-de-lenvironnement.html

Le Dansoir, http://ledansoir.saporta-danse.com/

On line tour of the Library, http://www.bnf.fr/visitefmitterrand/promenade/ps.htm 